\title{
A change in seasonality in Greenland during a Dansgaard-Oeschger warming
}

\author{
Elizabeth R. THOMAS, Robert MULVANEY, Eric W. WOLFF \\ British Antarctic Survey, Natural Environment Research Council, Madingley Road, Cambridge CB3 OET, UK \\ E-mail: lith@bas.ac.uk
}

\begin{abstract}
A new sub-seasonal chemical record is presented from the North Greenland Icecore Project (NorthGRIP) ice core during the onset of one of the longest and strongest interstadials of the last glacial period, Dansgaard-Oeschger event 8 (approximately 38000 years ago). This is the first time that a record of such resolution has been achieved over several metres of deep glacial ice and provides a unique opportunity for using additional parameters to carry out accurate dating using annual-layer counting. The very high-resolution chemical data were used to assess the phasing of various ions and determine changes in the seasonal strength of chemical deposition and the shape of the seasonal cycle. The study shows that a change in seasonality accompanied the dramatic warming transition from stadial to interstadial conditions in Greenland.
\end{abstract}

\section{INTRODUCTION}

Large temperature variations are observed during the last glacial period in the isotope record from Greenland ice cores, where they are known as Dansgaard-Oeschger (DO) events (Bond and others, 1993; Dansgaard and others, 1993; Grootes and others, 1993; Taylor and others, 1993; Mayewski and others, 1997). The abrupt jumps in temperature of $9-16^{\circ} \mathrm{C}$, from periods of extreme cold to relatively warm conditions, lasted from a few centuries to several thousand years (Lang and others, 1999; Severinghaus and Brook, 1999) and followed a general pattern of an abrupt warming and gradual cooling.

In this paper, we investigate DO event 8 (DO-8), one of the most prominent interstadials of the last glacial period observed during marine isotope stage 3 (MIS 3) approximately 38 kyr BP (before present, 1950), according to the GICC05 dating (Andersen and others, 2006). It follows Heinrich event $4(\mathrm{H} 4)$, a period characterized by high concentrations of ice-rafted debris (IRD) in North Atlantic sediment cores (Heinrich, 1988) and extreme cold conditions in Greenland. We present annual-layer counting of a new sub-seasonal resolution $(2 \mathrm{~mm})$ chemical record from the North Greenland Icecore Project (NorthGRIP) ice core (NorthGRIP members, 2004) at the onset of interstadial 8 (DO-8). The layer thickness determined using this new method is compared with the new GICC05 dating (Andersen and others, 2006) and analyzed in terms of alterations in strength of deposition and seasonality in Greenland during the warming transition. This is the first time that this resolution has been achieved at this ice depth for several metres of glacial ice.

\section{METHOD}

Sections of the NorthGRIP core, between 2068.5 and $2073 \mathrm{~m}$ (38 118-38 350 years BP (1950), or 38 168-38 $400 \mathrm{yr}$ b2k, on the GICC05 timescale; note that the dates in the official GICC05 timescale (Andersen and others, 2006) were given as years before AD $2000(\mathrm{~b} 2 \mathrm{k})$, and therefore have to be adjusted by 50 years to map them onto the BP dates commonly used in other communities), corresponding to the warming transition into DO-8, were cut into discrete samples of $2 \mathrm{~mm}$ thickness. Due to the exceptionally small sample size, a new cutting method using a microtome device and a low-volume ion chromatography method was developed.

The section of ice used in this study was from the outermost part of the ice core; the outer surfaces were removed using a bandsaw to prevent contamination from drilling fluid and handling. A sledge microtome was then used to cut $2 \mathrm{~mm}$ samples (using several passes of the blade to cut a succession of $40 \mu \mathrm{m}$ shavings), with no ice loss, that were placed in clean Coulter accuvettes for melting and then transferred into clean ion-chromatography auto-sampler vials for analysis. Powder-free gloves and protective clothing were worn throughout to minimize contamination.

Ion chromatography (IC) was used to determine five anions, chloride $\left(\mathrm{Cl}^{-}\right)$, fluoride $\left(\mathrm{F}^{-}\right)$, methanesulphonate $\left(\mathrm{MSA}^{-}\right)$, nitrate $\left(\mathrm{NO}_{3}{ }^{-}\right)$and sulphate $\left(\mathrm{SO}_{4}{ }^{2-}\right)$. The system used was a reagent-free Dionex ICS-2500 with a $2 \mathrm{~mm}$ column and a $250 \mu \mathrm{L}$ sample loop. A potassium hydroxide eluent generator cartridge (EGC-OH) was used to reduce operational errors and contamination associated with eluent preparation. The flow was set to $0.25 \mathrm{~mL} \mathrm{~min}^{-1}$ with an isocratic elution of $23 \mathrm{~mm} \mathrm{KOH}$. Four cations, calcium $\left(\mathrm{Ca}^{2+}\right)$, potassium $\left(\mathrm{K}^{+}\right)$, sodium $\left(\mathrm{Na}^{+}\right)$and magnesium $\left(\mathrm{Mg}^{+}\right)$, were analyzed using a reagent-free Dionex IC-2000 $3 \mathrm{~mm}$ column and $250 \mu \mathrm{L}$ sample loop. The cation system is equipped with an MSA eluent generator cartridge and the method followed set the flow to $0.5 \mathrm{~mL} \mathrm{~min}^{-1}$ with an isocratic elution of $20 \mathrm{~mm} \mathrm{MSA}$.

A sequential flow method was used to analyze both anions and cations from the same sample vial, using a Dionex AS50 auto-sampler, thus minimizing sample volume requirements. The sample and the anion eluent are passed from the ICS-2500 system into the IC-2000 system. Tests of this method were made using frozen ultra-pure water to show that the blanks were negligible $(<5 \%$ of glacial concentration levels) for all ions (Thomas, 2006).

\section{Annual-layer counting}

The chemical composition of ice cores and snow pits is dependent on atmospheric and precipitation chemistry (Barrie, 1995; O'Brien and others, 1995; De Angelis and others, 1997). It is possible to relate changes in the concentrations 


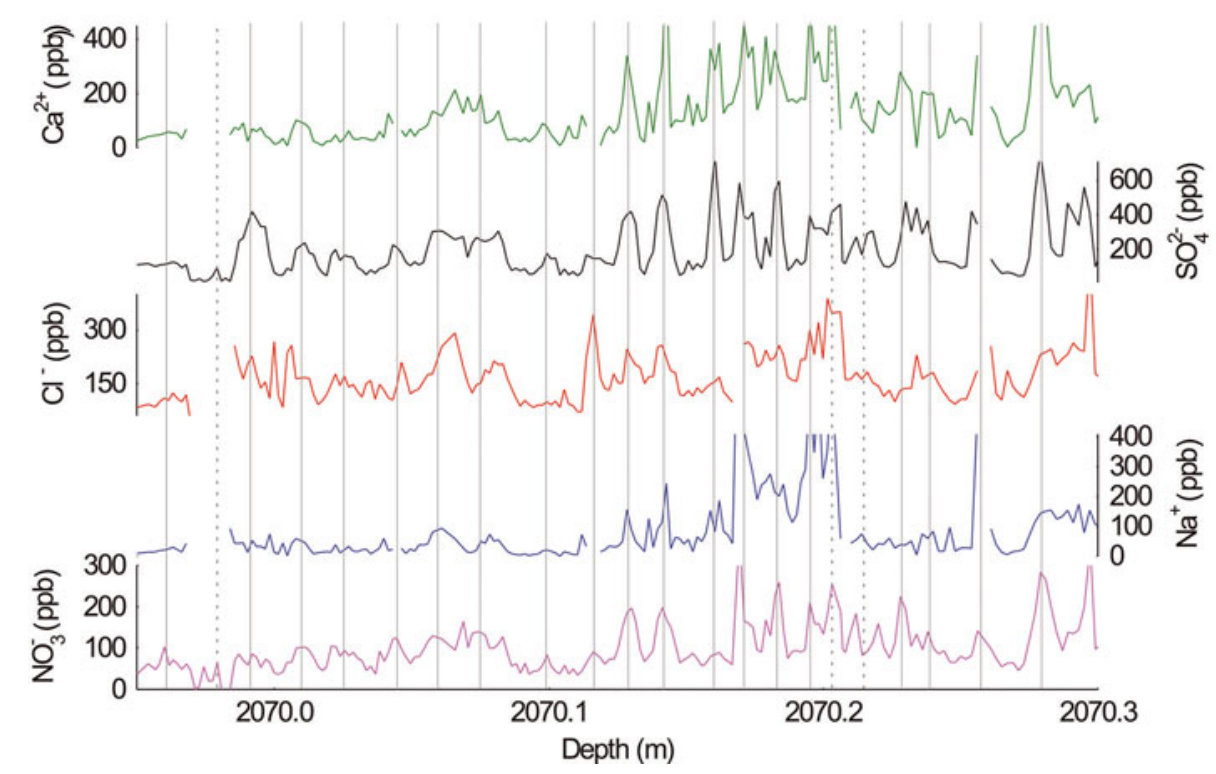

Fig. 1. Annual layers determined from calcium, sulphate, chloride, sodium and nitrate at $2 \mathrm{~mm}$ resolution. This section spans $\sim 23$ years across the warming transition at the onset of DO-8 between 2069.95 and $2070.3 \mathrm{~m}$, approximately $38166-38189$ years ago.

of ions in the ice to changes in the atmospheric composition, caused by factors such as different transport pathways or source areas at different times of the year. The continental ions $\left(\mathrm{Ca}^{2+}\right.$ and $\left.\mathrm{Mg}^{2+}\right)$ are indicative of long-range atmospheric loading and dustiness from East Asia (Biscaye and others, 1997; Svensson and others, 2000; Bory and others, 2003), while the ions that have a major component of marine origin $\left(\mathrm{Cl}^{-}, \mathrm{Na}^{+}, \mathrm{SO}_{4}{ }^{2-}\right.$ and $\left.\mathrm{MSA}^{-}\right)$represent vigour of atmospheric circulation and are determined by the location and strength of oceanic sources and atmospheric transport from them. Analyzing the ions at a sub-seasonal scale enables us to observe these alterations in concentration throughout the year to pick up a seasonal signal.

The distinct annual cycles in the chemical record can be counted using the peaks and troughs of each ion. Ice compression, at the depths investigated, results in exceptionally thin annual layers of $<2 \mathrm{~cm}$ (an average of $1.6 \mathrm{~cm}$ during the stadial and $3 \mathrm{~cm}$ during the interstadial based on the GICC05 dating (Andersen and others, 2006)). The new $2 \mathrm{~mm}$ resolution analysis provided a sub-seasonal record, of up to ten samples per year, with clear seasonal cycles in all ions.

Each annual layer was determined by locating a peak (maximum) followed by a trough (minimum) in all ions. Years were confidently assigned (marked with a solid vertical line in Fig. 1) if a near-synchronous (within the same determined layer) peak was observed in calcium, chloride, nitrate, sodium and sulphate; these were considered to be the most robust and reliable indicators of seasonal deposition in this study. For consistency the depth of each annual layer was taken as the centre point of the nitrate peak. In sections where there were missing data, as a result of either damaged ice or insufficient liquid sample for analysis, a dashed vertical line has been added. This also applies to sections of ice where the annual signal is obscured or some doubt exists as to the location of the peak. With regard to the annual-layer counting, each dashed line denotes a year of uncertainty.

The annual layers were counted for $2.7 \mathrm{~m}$ of ice analyzed over the warming transition, between depths 2068.6 and $2071.3 \mathrm{~m}$. The clearest cycles were observed in the records of calcium, chloride, nitrate, sodium and sulphate. However, the seasonal signal during the stadial, in the section of ice prior to the warming, differs considerably from that of the interstadial ice. The two sections are compared across the warming transition between depths of 2069.95 and $2070.3 \mathrm{~m}$ in Figure 1. The oxygen isotope $\left(\delta^{18} \mathrm{O}\right)$ signal (not shown) changes rapidly during this period, with the onset of the interstadial observed at $2070.14 \mathrm{~m}$ depth (38176 years BP) (Thomas, 2006).

\section{Comparison with GICC05}

The new GICC05 dating for the last glacial period (Andersen and others, 2006) was produced using a chemical record from continuous flow analysis, electrical conductivity measurements (ECM) and visual stratigraphy. The number of years determined using the GICC05 method (K.K. Andersen, unpublished data) between depths 2068.60 and $2071.30 \mathrm{~m}$ is 123 marked as 'certain', plus 12 marked as uncertain, while 141 were counted in this study for the same section, of which 6 are uncertain. The two dating methods are comparable, within the quoted uncertainties, as shown in Figure 2 which plots the layer thickness from GICC05 (blue curve) with the layer thickness determined in this study from the $2 \mathrm{~mm}$ chemistry record (red curve).

Despite the good agreement, the number of annual layers determined in this study is slightly higher than that of the GICC05 method. The GICC05 data during DO-8 were heavily reliant on visual stratigraphy and to a lesser extent ECM. The slight discrepancy in the dating is therefore probably due to the increased resolution of the $2 \mathrm{~mm}$ data compared to GICC05; this has either picked out annual layers that were missed by the GICC05 method, or has resolved additional sub-annual peaks that would have led to an over-count in our record.

\section{SEASONALITY}

We can use the very high-resolution chemical data to judge whether the seasonality of chemical deposition changed in the transition from stadial to interstadial conditions. 


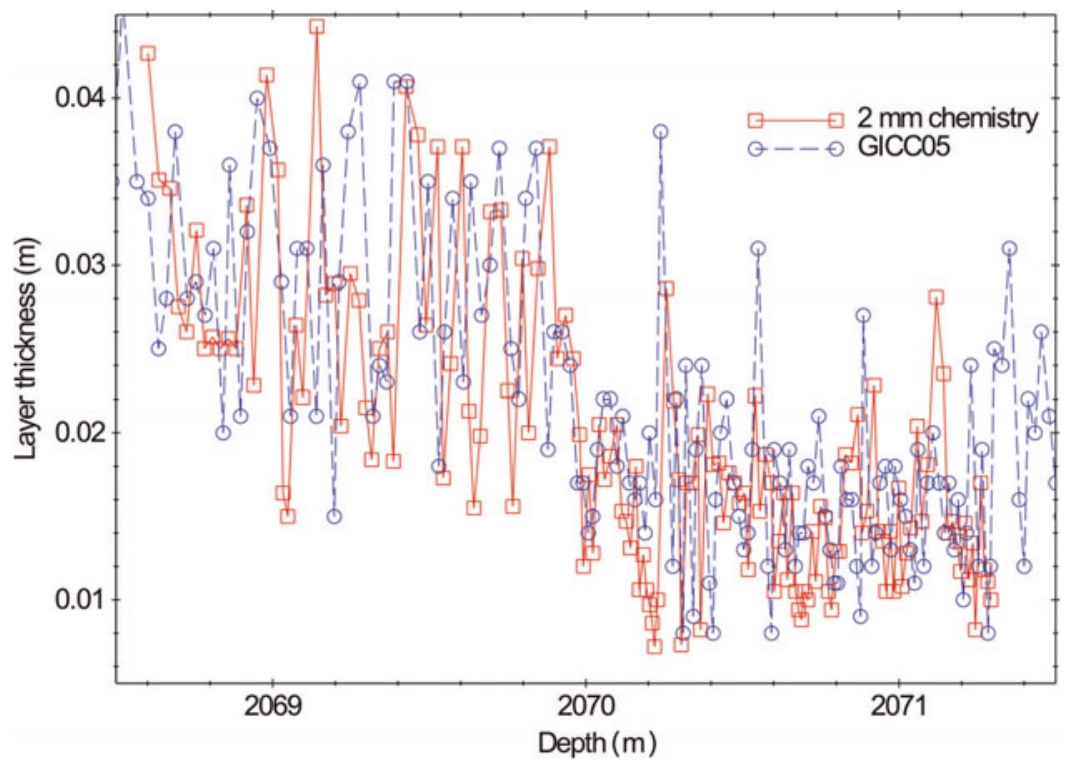

Fig. 2. Comparison of the annual-layer thickness derived from the layer counting of the $2 \mathrm{~mm}$ chemical record (red curve) and the GICC05 dating (blue curve; K.K. Andersen, unpublished data) during the warming transition at the onset of DO-8.

Increased deposition of dust on the Greenland ice sheet occurs in the present day during the spring (Whitlow and others, 1992), coincident with the most active period of dust storms in eastern Asia, the source of dust to Greenland (Biscaye and others, 1997; Bory and others, 2002, 2003). Without well-resolved seasonal temperature records for Greenland, it is not possible to determine if this period of maximum deposition also occurred in the spring during the glacial. However, in order to assess changes between stadial and interstadial conditions, it has been assumed to be the same. In this study, calcium is representative of dust, so the annual maximum of calcium observed in the NorthGRIP record is assumed to represent spring deposition, with the minimum falling in the late-summer/autumn months (hereafter known as late summer). In the stadial ice, the peaks of all ions are approximately synchronous with the centre point of the peak in each ion at the same depth. This is in conflict with the seasonality described by Whitlow and others (1992) for more recent ice; that study reported a difference in the phasing of various ions within the annual cycle. In the ice from the interstadial, the location of the various ions appears similar to that of the stadial with a spring peak in all ions at approximately the same depth, but the signal is less clear in the interstadial ice.

\section{Seasonal strength}

Due to ice thinning, resulting in a small number of data points each year, it is hard to determine all the seasons within an annual layer. For this reason, it has been assumed that peaks indicate a spring maximum, and troughs a latesummer minimum. In this way the maximum and minimum values within the annual cycle could be determined in order to assess the change in seasonal strength across the transition. The spring maximum value has been determined for all years in which enough data points were available to provide a reliable maximum and minimum. Care was taken to ensure that only years with more than five data points and a distinctive seasonal cycle (which included a maximum and minimum) were used, to capture a full year. Years marked as uncertain, where ice was broken or not enough data were available to confidently determine the maximum and minimum, were removed. In general there are clear maxima and minima in the glacial, which allows a degree of confidence that the maximum value within each year is in fact the spring peak and not an additional peak. In the interstadial, however, the annual signal was less clear.

There is a large degree of annual and decadal variability in the chemistry during the stadial, making it hard to determine a robust transition in the chemical record. Concentrations appear to drop above $2070.13 \mathrm{~m}$ depth, but it is only above $2070.05 \mathrm{~m}$ depth (coinciding with a calendar age of 38175 years BP (Thomas, 2006)) that concentrations of ions determined as continental in origin have reached interstadial levels, so this is considered the termination of the chemical transition. This chemical transition is observed considerably earlier than the isotope transition, which terminates 21 years later (Thomas, 2006), consistent with previous studies of $\mathrm{Ca}$ and $\delta^{18} \mathrm{O}$ during DO events of the last $50 \mathrm{kyr}$ (Mogensen and others, 2002), indicating that circulation changes occurred before the warming in Greenland. The concentration of the springtime maximum for calcium and sulphate shows a dramatic decrease at the warming transition, dropping $80 \%$ and $61 \%$ respectively, believed to be the result of reduced storminess in eastern Asia (Biscaye and others, 1997; Bory and others, 2003) or reduced residence time and dust mobilization (Fuhrer and others, 1999). The reduction in storm activity and associated reduction in uplift of dust to the Greenland ice sheet is consistent with paleoclimate evidence of increased strength of the East Asian monsoon in the region during warm interstadials in Greenland (Wang and others, 2001; Ruth and others, 2007). However, the change in concentration of the autumn minimum across the warming transition indicates that springtime storms were not the only factor to change.

The change in concentration of the late-summer minimum for calcium and sulphate, although smaller than the decrease in the spring maximum, is still significant, decreasing by $56 \%$ and $39 \%$ respectively. The ions that have a major component of marine origin, sodium and chloride, 

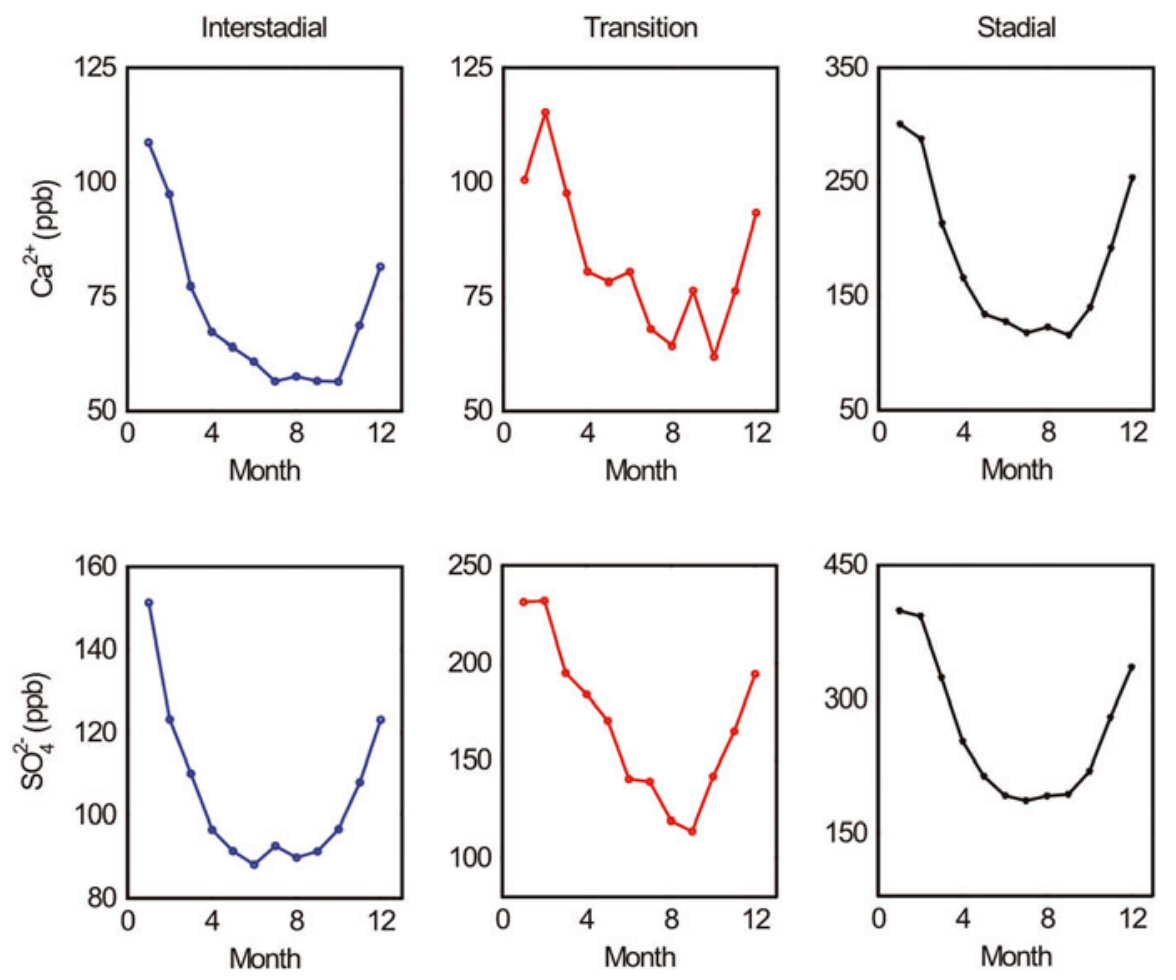

Fig. 3. Comparison of the mean seasonal cycle in calcium (top) and sulphate (bottom) during the stadial (black curve; 79 years), the transition (red curve; 5 years) and the interstadial (blue curve; 45 years). Note the changing $y$ axis, which emphasizes the change in the absolute concentration. The $x$ axis is accumulation months, as described in the text, with the spring minimum in Ca set to zero.

show a larger change in the concentration of the latesummer minimum than the change in spring maximum; decreasing $64 \%$ and $46 \%$ respectively for the late-summer minimum, and $30 \%$ and $15 \%$ for the spring maximum. Therefore it appears that changes in summertime deposition are greatest for the marine species, while spring deposition changes are the dominant factor in the continental species.

\section{Shape of the seasonal cycle}

The location in the depth profile of the annual layers has been used to determine the shape of the seasonal cycle and the relative phasing between chemical species throughout the warming transition. The concentration of each ion within a determined year has been divided into 12 increments of equal depth by a robust cubic-spline interpolation routine; for ease of description, we refer to these increments as 'accumulation months', although we recognize that we have no information about the distribution of snow accumulation through the year. As with the investigation of seasonal strength, only years with greater than five data points and a clear seasonal cycle with a distinct minimum and maximum were used. Years marked as uncertain in the annual-layer counting were not used. The seasonal cycle for each year can then be averaged to give a mean cycle for each ion during the stadial, the transition and the interstadial, as shown in Figures 3 and 4.

The period during the transition (red curves in Figs 3 and 4) is only based on 5 years (representing the drop to interstadial levels between 2070.13 and $2070.05 \mathrm{~m}$ ) and is therefore less robust than the periods before and after the warming, which are an average of 79 and 45 years respectively.

In Figure 3, calcium and sulphate have been compared during the stadial, the interstadial and during the transition. Both calcium and sulphate show a large change in the strength (concentration) of the spring maximum and latesummer minimum during the transition, as observed earlier. The general shape of the seasonal cycle is similar both before and after the transition, with a broad maximum and minimum at intervals of approximately half the accumulation year from each other. The decrease in deposition from the absolute maximum to the absolute minimum takes slightly longer during the interstadial than during the stadial, possibly indicating longer winters or additional spring deposition.

The general shape of the seasonal cycle for the marine ions (sodium and chloride) appears to change from the stadial to the interstadial, with a sharper (and for sodium, earlier) minimum for the interstadial. There is a distinct change in the seasonal cycle in the transition years (red curves in Fig. 3) for both species, but this is based on just 5 years of data. Sodium shows a shift in the maximum values, peaking later in the year.

Chloride shows an apparent change in the shape of the seasonal cycle from stadial to interstadial conditions, peaking earlier in the year and exhibiting increased deposition in early summer that punctuates the gradual decrease following the maximum. These changes in the seasonal cycle might be related to drastic changes in ocean circulation and sea-ice break-up, associated with DO events (Broecker and others, 1985).

The ratio of $\mathrm{Cl}^{-} / \mathrm{Na}^{+}$in the $2 \mathrm{~mm}$ chemical record was compared to that of standard sea water (1.8 from the handbook of marine science (Kennish, 2001)) to show variability across the warming transition (Thomas, 2006). Values of the ratio higher than those of sea water are observed during the interstadial, probably indicating the presence of deposition of $\mathrm{HCl}$ (as excess chloride) under warmer conditions. Such an increase in the ratio of $\mathrm{Cl}^{-} / \mathrm{Na}^{+}$ 

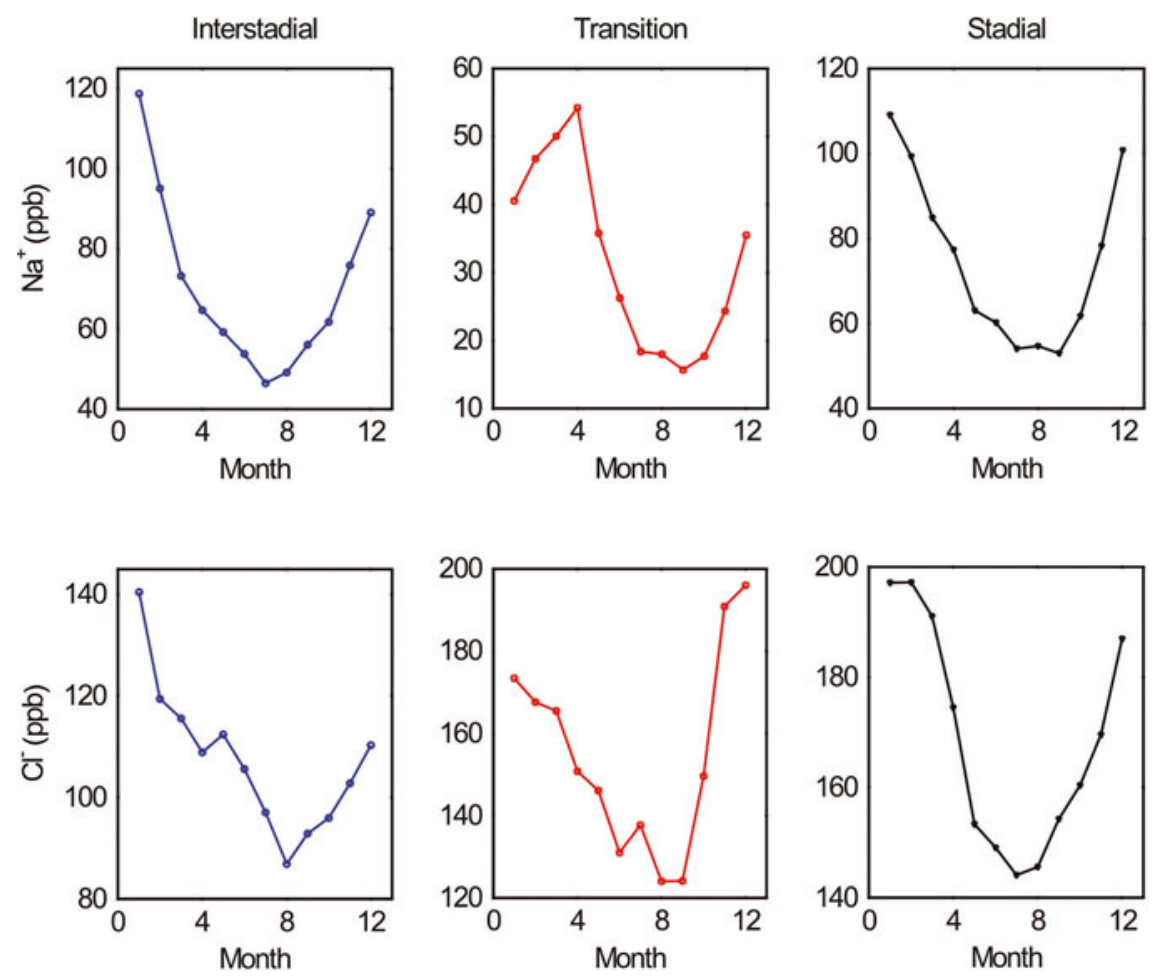

Fig. 4. Same as Figure 3, but for sodium (top) and chloride (bottom).

under warmer conditions was already noted for GRIP, although the interstadial/stadial contrast was not clearly defined (De Angelis and others 1997). The presence of excess chloride, expected to peak in summer (De Angelis and others 1997), may explain the differences in the shape of the seasonal cycle for the two marine ions during the interstadial.

A change in seasonality of precipitation is supported by model simulations run under glacial conditions (Krinner and others, 1997), and has been used to explain the discrepancy between borehole- and isotope-derived temperatures during the Last Glacial Maximum (Werner and others, 2000). This study has shown that there was a distinct seasonal change in chemical input during the DO-8 warming that was different for various ions. The change in seasonal strength was greatest during the spring for the continental and nonmarine species $\left(\mathrm{Ca}^{2+}, \mathrm{Mg}^{2+}, \mathrm{NO}_{3}{ }^{-}, \mathrm{SO}_{4}{ }^{2-}, \mathrm{K}^{+}\right)$, but greatest during the summer for the marine and non-continental species $\left(\mathrm{Na}^{+}, \mathrm{Cl}^{-}, \mathrm{F}^{-}, \mathrm{MSA}\right)$. This change in seasonality is also reflected in the shape of the seasonal cycle, with a longer period of summer deposition observed in calcium during the stadial than the interstadial. For the marine ions, sodium and chloride, there is a shift in the timing of the spring maximum.

\section{CONCLUSIONS}

DO-8 is observed as a large temperature jump of approximately $11.4^{\circ} \mathrm{C}$ (based on a glacial calibration $\left(0.33 \%{ }^{\circ} \mathrm{C}^{-1}\right.$ ) (Cuffey and others, 1995)) from cold stadial conditions to relatively warm interstadial conditions. The accumulation rate increased, accompanied by a dramatic change in atmospheric circulation or source conditions, indicated by the significant decrease in concentrations. The new chemical record is the first of this resolution for deep glacial ice and provides a unique opportunity not only for accurate dating but also to show that a change in seasonality occurred during the transition from stadial to interstadial conditions.

For the continental ions, there is a large decrease in the concentration of the spring maximum from stadial to interstadial, while the change in concentration of the latesummer minimum (although significant) is less dramatic. The opposite is true for the non-continental and marine ions, which show a larger decrease in the minimum concentrations than the maximum, indicating a greater change in deposition during late summer than during the spring.

The evidence that summertime deposition was also larger (for marine and non-continental species) prior to the warming at the onset of DO-8 indicates that both summers and winters were colder, at least in Greenland. This is consistent with stadial conditions in which sea ice is formed more readily on the colder North Atlantic water, forming a lid lasting most of the year (Overpeck and others, 1997). The resulting insulating sea ice prevents the relatively warm ocean water from heating the adjacent land masses and acts as an amplifier, reflecting sunlight and further cooling the region. Under these conditions it would be expected that summer conditions in Greenland and the North Atlantic region would be colder and drier.

The seasonal signal is robust, providing a reproducible dating method comparable to independent dating techniques. The new record has shown that large changes in seasonal strength and the shape of the seasonal cycle accompanied the dramatic warming at the onset of this DO event, although more records are needed to determine if this is true for other DO events.

\section{ACKNOWLEDGEMENTS}

This work is a contribution to the NorthGRIP ice-core project, which is directed and organized by the Ice and Climate Research Group at the Niels Bohr Institute, 
University of Copenhagen, Denmark. It is supported by funding agencies in Denmark (Danish Research Agency (SNF)), Belgium (Fonds National de la Recherche Scientifique (FNRS-CFB)), France (Institut Français de Recherche et Technologie Polaire (IFRTP) and Institut National des Sciences de I'Univers/Centre National de la Recherche Scientifique (INSU/CNRS)), Germany (Alfred Wegener Institute), Iceland (Icelandic Research Council (Rannls)), Japan (Ministry of Education, Culture, Sports, Science and Technology (MEXT)), Sweden (Swedish Polar Research Secretariat), Switzerland (Swiss National Science Foundation) and the United States (US National Science Foundation). We thank K.K. Andersen for the GICC05 data, and A. Svensson and M. Hansson for their comments. This research was funded by the UK Natural Environment Research Council's Rapid Climate Change (RAPID) programme.

\section{REFERENCES}

Andersen, K.K. and 11 others. 2006. The Greenland Ice Core Chronology 2005, 15-42 ka. Part 1: constructing the time scale. Quat. Sci. Rev., 25(23-24), 3246-3257.

Barrie, L.A. 1995. Arctic aerosols: composition, sources and transport. In Delmas, R.J., ed. Ice core studies of global biogeochemicl cycles. Berlin, etc., Springer-Verlag, 1-22.

Biscaye, P.E. and 6 others. 1997. Asian provenance of glacial dust (stage 2) in the Greenland Ice Sheet Project 2 ice core, Summit, Greenland. J. Geophys. Res., 102(C12), 26,765-26,781.

Bond, G. and 6 others. 1993. Correlations between climate records from North Atlantic sediments and Greenland ice. Nature, 365(6442), 143-147.

Bory, A.J.-M., P. Biscaye, A. Svensson, and F. Grousset. 2002. Seasonal variability in the origin of recent atmospheric mineral dust at NorthGRIP, Greenland. Earth Planet. Sci. Lett., 196(3-4), 123-134.

Bory, A.J.-M., P.E. Biscaye and F.E. Grousset. 2003. Two distinct seasonal Asian source regions for mineral dust deposited in Greenland (NorthGRIP). Geophys. Res. Lett., 30(4), 1167. (10.1029/2002GL016446.)

Broecker, W.S., D.M. Peteet and D. Rind. 1985. Does the oceanatmosphere system have more than one stable mode of operation? Nature, 315(6014), 21-26.

Cuffey, K.M., G.D. Clow, R.B. Alley, M. Stuiver, E.D. Waddington and R.W. Saltus. 1995. Large Arctic temperature change at the Wisconsin-Holocene glacial transition. Science, 270(5235), 455-458.

Dansgaard, W. and 10 others. 1993. Evidence for general instability of past climate from a 250-kyr ice-core record. Nature, 364(6434), 218-220.

De Angelis, M., J.P. Steffensen, M. Legrand, H. Clausen and C. Hammer. 1997. Primary aerosol (sea salt and soil dust) deposited in Greenland ice during the last climatic cycle: comparison with East Antarctic records. J. Geophys. Res., 102(C12), 26,68126,698.

Fuhrer, K., E.W. Wolff and S.J. Johnsen. 1999. Timescales for dust variability in the Greenland Ice Core Project (GRIP) ice core in the last 100,000 years. J. Geophys. Res., 104(D24), 31,043-31,052.

Grootes, P.M., M. Stuiver, J.W.C. White, S. Johnsen and J. Jouzel. 1993. Comparison of oxygen isotope records from the GISP2 and GRIP Greenland ice cores. Nature, 366(6455), 552-554.

Heinrich, H. 1988. Origin and consequences of cyclic ice rafting in the northeast Atlantic Ocean during the past 130,000 years. Quat. Res., 29(2), 142-152.

Kennish, M.J. 2001. Practical handbook of marine science. Third edition. Boca Raton, FL, CRC Press.

Krinner, G., C. Genthon and J. Jouzel. 1997. GCM analysis of local influences on ice core $\delta$ signals. Geophys. Res. Lett., 24(22), 2825-2828.

Lang, C., M. Leuenberger, J. Schwander and S. Johnsen. 1999. $16^{\circ} \mathrm{C}$ rapid temperature variation in central Greenland 70,000 years ago. Science, 286(5441), 934-937.

Mayewski, P.A. and 6 others. 1997. Major features and forcing of high-latitude Northern Hemisphere atmospheric circulation using a 110,000-year-long glaciochemical series. J. Geophys. Res., 102(C12), 26,345-26,366.

Mogensen, I.A., S.J. Johnsen, A. Ganoploski and S. Rahmstorf. 2002. An investigation of rapid warm transitions during MIS2 and MIS3 using Greenland ice-core data and the CLIMBER-2 model. Ann. Glaciol., 35, 398-402.

North Greenland Ice Core Project (NorthGRIP) Members. 2004. High-resolution record of Northern Hemisphere climate extending into the last interglacial period. Nature, 431(7005), 147-151.

O'Brien, S.R., P.A. Mayewski, L.D. Meeker, D.A. Meese, M.S. Twickler and S.I. Whitlow. 1995. Complexity of Holocene climate as reconstructed from a Greenland ice core. Science, 270(5244), 1962-1964.

Overpeck, J. and 17 others. 1997. Arctic environmental change of the last four centuries. Science, 278(5341), 1251-1256.

Ruth, U. and 9 others. 2007. Ice core evidence for a very tight link between North Atlantic and east Asian glacial climate. Geophys. Res. Lett., 43(3), L03706. (10.1029/2006GL027876.)

Severinghaus, J.P. and E.J. Brook. 1999. Abrupt climate change at the end of the last glacial period inferred from trapped air in polar ice. Science, 286(5441), 930-934.

Svensson, A., P.E. Biscaye and F.E. Grousset. 2000. Characterization of late glacial continental dust in the Greenland Ice Core Project ice core. J. Geophys. Res., 105(D4), 4637-4656.

Taylor, K.C. and 9 others. 1993. Electrical conductivity measurements from the GISP2 and GRIP Greenland ice cores. Nature, 366(6455), 549-552.

Thomas, E.R. 2006. High-resolution analysis of rapid climate change from Greenland ice cores. (PhD thesis, Open University.)

Wang, Y.J. and 6 others. 2001. A high-resolution absolute-dated Late Pleistocene monsoon record from Hulu Cave, China. Science, 294(5550), 2345-2348.

Werner, M., U. Mikolajewicz, M. Heimann and G. Hoffmann. 2000. Borehole versus isotope temperatures on Greenland: seasonality does matter. Geophys. Res. Lett., 27(5), 723-726.

Whitlow, S., P.A. Mayewski and J.E. Dibb. 1992. A comparison of major chemical species seasonal concentration and accumulation at the South Pole and Summit, Greenland. Atmos. Environ., 26A(11), 2045-2054. 